\title{
Predictors of post-operative outcomes in patients with peripheral arterial disease and critical limb ischaemia: a systematic review and meta-analysis
}

\author{
Lily P. Wu ${ }^{1}$, Nadraj G. Naidoo ${ }^{3}$ and Olatunji O. Adetokunboh ${ }^{4}$ \\ Ghana Med J 2020; 55(1): 69-76 doi: http://dx.doi.org/10.4314/gmj.v55i1.10 \\ ${ }^{1}$ University of Ghana College of Health Sciences, Surgery Department, Legon, Accra, Ghana \\ ${ }^{3}$ South African Medical Research Council South African Medical Research Council, Tygerberg, South Africa \\ ${ }^{4}$ University of Cape Town Faculty of Health Sciences, Surgery, Observatory, Western Cape, South Africa
}

\author{
Corresponding author: Lily P. Wu \\ Conflict of interest: None declared
}

E-mail: lily.mp.wu@gmail.com

\begin{abstract}
SUMMARY
Background: A very small proportion (1\%) of patients with peripheral artery disease (PAD) present with critical limb threatening ischaemia (CLTI) with poor prognosis. The present review showcased several pre-operative predictors and key post-operative outcomes. Identification of any modifiable predictors may impact positively on surgical outcomes.

Design: PubMed/Medline, Google scholar and Cochrane databases were searched using terms such as "peripheral arterial disease" AND "critical limb ischemia," "post-operative outcome," AND "predictors of post-operative outcomes". Search was for relevant English-language articles published between January 1997 and December 2007 Selected articles were screened first by title and abstract, and selection of full articles was based on relevance using our inclusion and exclusion criteria and quality ratings performed with the MINORS score.

Results: The included studies were published between 1997 and 2007. Only six (6) articles out of a total of 2,114 were deemed suitable for analysis. Ambulatory recovery was $>70 \%$ at six months, $86.7 \%$ and $70.0 \%$ at one year and five years respectively. Rate of local wound complications was between $12 \%$ and $24 \%$. Reported limb salvage rates were $>90 \%$ at six months, $>70 \%$ at one year and $70.0-90.0 \%$ at five years. Primary graft patency rate at one year ranged from $63 \%$ and $76.6 \%$. Gangrene, diabetes and impaired pre-operative ambulatory function are associated with more wound complications, low limb salvage, reduced graft patency and poor functional outcome.

Conclusion: Pre-operative ambulatory status was the most important predictor of post-operative ambulatory recovery. Diabetes mellitus was an important risk factor for prolonged wound healing, local wound complications and major amputation.
\end{abstract}

Keywords: Peripheral arterial disease, critical limb ischemia, post-operative outcomes Funding: None declared

\section{INTRODUCTION}

Assessment of post-operative outcomes of vascular intervention for CLTI is increasingly shifting from traditional technical outcomes such as graft patency and limb-salvage, ${ }^{1}$ to functional outcomes such as ambulatory recovery and wound healing rates. ${ }^{2-6}$ Functional outcomes have been shown in recent reports to be better outcome measures to assess clinical success of operative interventions for CLTI. Simons et al. showed that despite adequate $(>70 \%)$ graft patency and limb salvage, $10 \%$ of patients with patent grafts at 1year still could not attain clinical success of ambulatory recovery and independent living. ${ }^{5}$ In a study by Taylor et al, clinical success was defined as achieving all the following criteria: graft patency to the point of wound healing; limb salvage at one year; maintenance of ambulatory status for one year; and survival at six months.
Despite $>70 \%$ limb salvage and graft patency at three years, only $44.4 \%$ of the patients achieved the composite endpoint of clinical success as stated above. ${ }^{3}$ Goshima et al showed that time to heal exceeded three months in $>50 \%$ of patients and that diabetes mellitus was a risk factor for prolong wound healing. ${ }^{2}$ Taylor et al. have suggested that a combination of traditional and functional outcomes is superior in the assessment of post-operative outcome post-intervention for CLTI. ${ }^{3}$

We undertook this meta-analysis in an effort to showcase-from the available literature - what specific pre-operative predictors most definitely affect both technical and functional post-operative outcomes. 


\section{METHODS}

\section{Literature search}

PubMed/Medline, Google scholar and Cochrane databases were systematically searched for relevant Englishlanguage articles published between January 1997 and December 2007 using the terms "peripheral arterial disease", "critical limb ischemia," AND "predictors of postoperative outcome". Selected articles were screened first by title and abstract, and selection of full-text articles was based on relevance. This study was approved by the Departmental (Surgical) Research Committee of Groote Schuur Hospital and the Human Research Ethics Committee of the University of Cape Town.

Inclusion criteria was published articles on CLTI involving patients' risk factor profile and at least three post-operative outcome measures (technical, functional or both). Reviews, case reports, abstracts only, meta-analysis and non-English articles and duplicate articles were excluded. Primary endpoint was technical and/or functional post-operative outcomes. Secondary endpoint was predictors of post-operative outcomes.

\section{Validity assessment}

Article screening, selection and data extraction were done by two individuals independently to minimize bias. Identified relevant titles were selected as an initial step. All abstracts were read, and articles with clearly stated objectives of evaluation of predictors of post-operative outcomes of surgical treatment of CLTI were chosen. Full articles were read, and selection made based on the presence of at least three outcome measures as defined in the reporting standards of revascularization for CLTI (technical outcome measures) and/or functional outcomes or both. ${ }^{7}$ All related publications/electronic links of the selected articles were downloaded and the references carefully reviewed to generate any further relevant publications. The quality of the selected articles was assessed using the MINORS quality score, with a maximum score of 16 for non-comparative studies and 24 for comparative studies (Figure 1). ${ }^{8}$

Methodological items for non-randomized studies

1. A clearly stated aim: the question addressed should be precise and relevant in the light of available literature

2. Inclusion of consecutive patients: all patients potentially fit for inclusion (satisfying the criteria for inclusion) have been included in the study during the study period (no exclusion or details about the reasons for exclusion)

3. Prospective collection of data: data were collected according to a protocol established before the beginning of the study

4. Endpoints appropriate to the aim of the study: unambiguous explanation of the criteria used to evaluate the main outcome which should be in accordance with the question addressed by the study. Also, the endpoints should be assessed on an intention-to-treat basis.

5. Unbiased assessment of the study endpoint: blind evaluation of objective endpoints and double-blind evaluation of subjective endpoints. Otherwise the reasons for not blinding should be stated

6. Follow-up period appropriate to the aim of the study: the follow-up should be sufficiently long to allow the assessment of the main endpoint and possible adverse events

7. Loss to follow up less than $5 \%$ : all patients should be included in the follow up. Otherwise, the proportion lost to follow up should not exceed the proportion experiencing the major endpoint

8. Prospective calculation of the study size: information of the size of detectable difference of interest with a calculation of 95\% confidence interval, according to the expected incidence of the outcome event, and information about the level for statistical significance and estimates of power when comparing the outcomes

Additional criteria in the case of comparative study

9. An adequate control group: having a gold standard diagnostic test or therapeutic intervention recognized as the optimal intervention according to the available published data

10. Contemporary groups: control and studied group should be managed during the same time period (no historical comparison)

11. Baseline equivalence of groups: the groups should be similar regarding the criteria other than the studied endpoints. Absence of confounding factors that could bias the interpretation of the results

12. Adequate statistical analyses: whether the statistics were in accordance with the type of study with calculation of confidence intervals or relative risk

${ }^{\dagger}$ The items are scored 0 (not reported), 1 (reported but inadequate) or 2 (reported and adequate). The global ideal score being 16 for non-comparative studies and 24 for comparative studies.

Figure 1 MINORS quality score

\section{RESULTS}

\section{Description of studies}

The literature search yielded 2,114 publications. A total of 1,147articles were selected after excluding irrelevant articles based on the titles and abstracts.
Over a 10-year period, 821 articles were selected. Based on human subjects above the age of 19 years, 590 articles were identified. Only six publications were identified as suitable for our study with three or more post-operative outcome measures (Figure 2). The included studies were published between 1997 and 2007. MINORS scoring scale (Table 1). 


\section{Special Article}

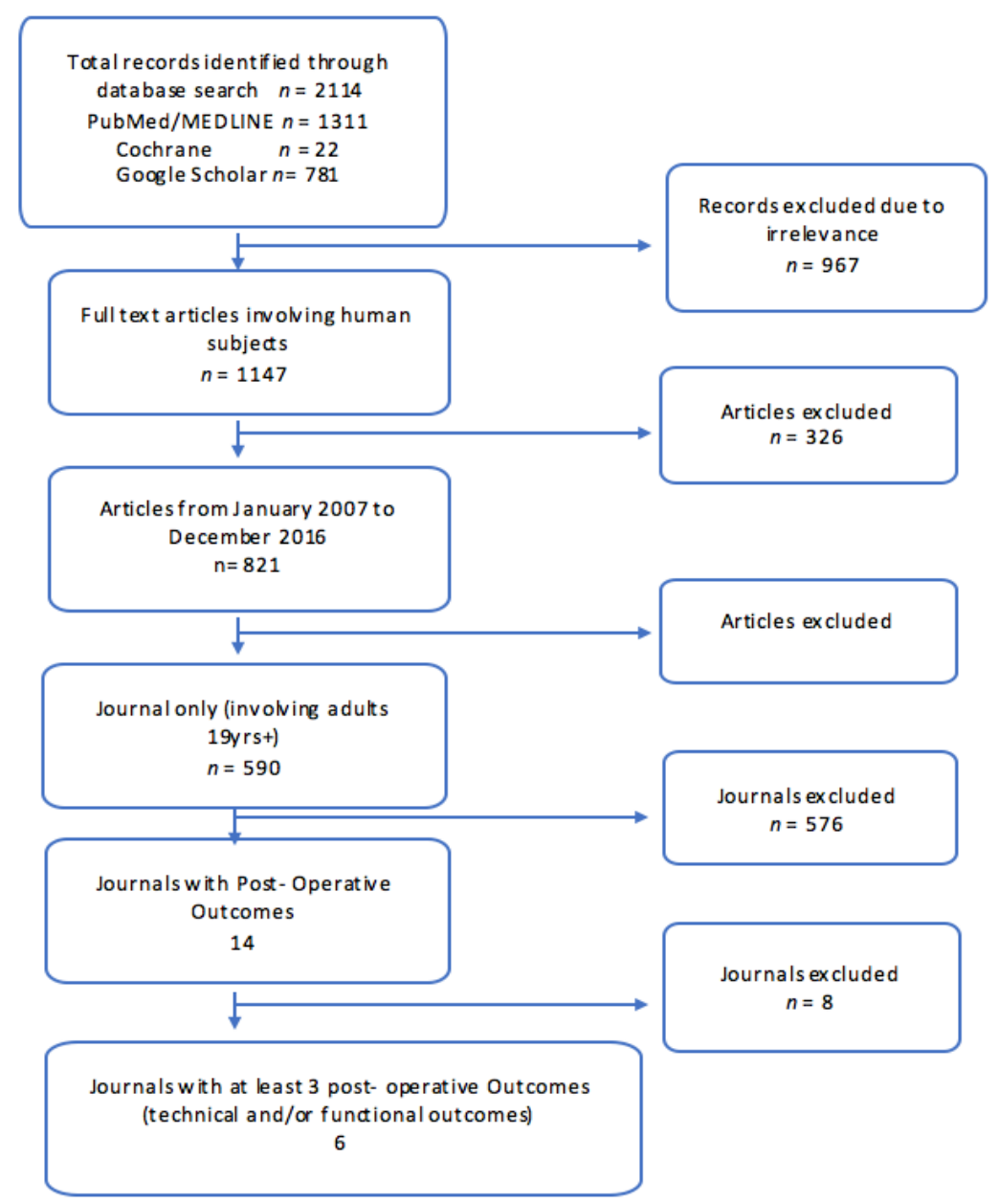

Figure 2 Flowchart of literature Search

The selected studies were of moderate quality using the MINORS scoring scale (Table 1).

Table 1 MINORS Score (6 Best performing Studies)

\section{MINORS Score}

\section{A clearly stated aim}

Inclusion of consecutive patients

Prospective collection of data

Endpoints appropriate to the aim of the $2 \quad 2 \quad 2 \quad 2 \quad 2 \quad 2$

study

Unbiased assessment of the study endpoints

Follow-up period appropriate to the aim of

the study

Loss to follow up less than $5 \%$

Prospective calculation of the study size

Total

\begin{tabular}{|l|l|l|l|l|l|}
\hline Study Number (see KEY) \\
\hline 1 & 2 & 3 & 4 & 5 & 6 \\
\hline 2 & 2 & 2 & 2 & 2 & 2 \\
\hline 2 & 2 & 2 & 2 & 2 & 2 \\
\hline 0 & 0 & 2 & 0 & 0 & 0 \\
\hline 2 & 2 & 2 & 2 & 2 & 2 \\
\hline 2 & 2 & 2 & 2 & 2 & 2 \\
\hline 1 & 2 & 2 & 0 & 2 & 2 \\
\hline 2 & 0 & 2 & 0 & 0 & 0 \\
\hline 0 & 0 & 0 & 0 & 0 & 0 \\
\hline 11 & 10 & 14 & 8 & 10 & 10 \\
\hline
\end{tabular}

KEY: 1. Goshima et al, 2. Taylor et al, 3. Taylor et al 4. Abou-Zamzam et al, 5. Nicoloff et al, 6. Chung et al.
The total sample size of the six eligible studies was 2,446 (Sample size range: 112-841patients) with a mean follow-up of 40.5 months for four studies. In the remaining two studies, the duration of follow up was not stated. All six studies reported a combination of technical and functional outcomes but at different timelines. Technical outcome measures were based on the standards for reporting by the Society for Vascular Surgery/International Society for Cardiovascular Surgery. ${ }^{1,7}$ Five of them were retrospective studies and one was a prospective study (Table 2a). The study population was grouped based on the investigated outcome measures and timelines at which the outcomes were assessed (Table 2b).

\section{Outcome measures and predictive factors}

Ambulatory recovery varied significantly, $72 \%$ to $92 \%$ at six months, $86.7 \%$ at one year, $73 \%$ at three years and 
$70.6 \%$ at five years. Rates of local wound complications reported were between $12 \%$ and $24 \%$. In some studies, more than $50 \%$ of the ischemic wounds took longer than four months to heal. In one study, the wound healing rates at six months and one year were $42 \%$ and $75 \%$ respectively. Reported limb salvage rates were from $94.2 \%$ at six months to $76.5-85.0 \%$ at one year. The five years' limb salvage rates were $72.1-91 \%$. Primary graft patency rate at one year was between $63 \%$ and $76.6 \%$. Major amputation rates varied widely from $3.5 \%$ at three months to $23.2 \%$ at three years. Survival at six months, one year and five years were $>80 \%, 89 \%$ and $48 \%$ respectively.

Table $2 \mathrm{c}$ shows some of the reported pre-operative risk factors. Only three included studies expressed those factors as odds ratios or hazard ratios while others reported as percentage or just in narrative format. Multiple factors influenced post-operative outcomes. Tissue loss and diabetes mellitus were associated with multiple re-operations and prolong wound healing. ${ }^{2,10}$ Gangrene, Diabetes, ESRD and impaired pre-operative ambulatory function predicted low limb salvage, reduced graft patency and poor functional outcome., ${ }^{4,9}$ Pre-operative impaired ambulatory function was reported in most of the studies to be the most important predictor of sub-optimal post-operative functional outcome. ${ }^{4,9,11}$ A composite endpoint of limb salvage and ambulation at one year, survival at six months and graft patency up to the point of healing was achieved in only $44 \%$ of patients. ${ }^{3}$

Some studies investigated predictors of post-operative outcome but the spectrum of outcome measures assessed were fewer than the minimum of 3 selected for our study and therefore were excluded. ${ }^{5,12}$ Other studies with sample population of patients who had re- intervention for failed previous vascular interventions were also excluded (Table 3). ${ }^{13,14}$

Out of the total of six eligible studies, only five studies were used in conducting the meta-analysis. The study that was excluded from meta-analysis did not report the outcomes at the timelines of interest. There is a high level of heterogeneity in the timelines for the various outcome measures in the papers evaluated (Figure 3a, b, c, d). Multiple factors predict post-operative outcomes.

Table 2a Included studies

\begin{tabular}{|c|c|c|c|c|}
\hline Study & $\mathbf{n}$ & Type of Study & Follow up (months) & Type of operation \\
\hline Goshima et al $2004^{2}$ & 315 & Retrospective & Not reported & Infra-inguinal bypass surgery \\
\hline Taylor et al $2007^{3}$ & 331 & Retrospective & 72 & Infra-inguinal and supra-inguinal bypass surgery \\
\hline Taylor et al $2006^{4}$ & 841 & Prospective & 60 & $\begin{array}{l}\text { Open revascularization, Endovascular interven- } \\
\text { tion and hybrid procedures }\end{array}$ \\
\hline Abou-Zamzam et al $1997^{9}$ & 513 & Retrospective & Not reported & Infra-inguinal bypass surgery \\
\hline Nicoloff et al $1998^{6}$ & 112 & Retrospective & 36 & Infra-inguinal bypass surgery \\
\hline Chung et al $2006^{10}$ & 334 & Retrospective & 30 & Infra-inguinal bypass surgery \\
\hline Total & 2,446 & & & \\
\hline
\end{tabular}

$\mathrm{n}=$ Number of Patients (Sample size)

Table 2b Included studies

\begin{tabular}{|c|c|c|c|c|c|c|c|}
\hline Study & & $\begin{array}{l}\text { Goshima } \\
\text { et al } 2004\end{array}$ & $\begin{array}{l}\text { Taylor et al } \\
2007\end{array}$ & $\begin{array}{l}\text { Taylor et } \\
\text { al } 2006\end{array}$ & $\begin{array}{l}\text { Abou-Zam- } \\
\text { zam et al } \\
1997\end{array}$ & $\begin{array}{l}\text { Nicoloff et } \\
\text { al } 1998\end{array}$ & $\begin{array}{l}\text { Chung et al } \\
2006\end{array}$ \\
\hline \multirow[t]{4}{*}{ Limb Salvage (\%) } & 6 months & & & & 94.2 & 94.9 & 85 \\
\hline & 1 year & & 80.6 & 76.5 & & & \\
\hline & 3 years & & & & & 93.5 & 79.0 \\
\hline & 5 years & 91 & & 72.1 & 85.2 & & \\
\hline \multirow{4}{*}{$\begin{array}{l}\text { Primary Graft Patency } \\
(\%)\end{array}$} & 6 months & & & & 92.0 & 93.1 & \\
\hline & 1 year & & & 76.6 & & & 63.0 \\
\hline & 3 years & & & & & 87.6 & 50.0 \\
\hline & 5 years & & & 72.4 & & & \\
\hline \multirow{4}{*}{$\begin{array}{l}\text { Ambulatory recovery } \\
(\%)\end{array}$} & 6 months & & & & 80.0 & 92.0 & 72.0 \\
\hline & 1 year & & 86.7 & & & & \\
\hline & 3 years & & & & & 73.0 & \\
\hline & 5 years & & & 70.6 & & & \\
\hline \multirow{2}{*}{ Wound Healing (\%) } & 6 months & 54.0 & & & 12.0 & & 42.0 \\
\hline & 1 year & & & & & & 75.0 \\
\hline
\end{tabular}




\section{Special Article}

Table 2c Included studies with reported pre-operative risk factors

\begin{tabular}{|c|c|c|}
\hline Included studies & Outcomes & Reported pre-operative risk factors \\
\hline \multirow[t]{5}{*}{ Goshima [2] } & Delayed wound healing & Diabetes mellitus (odds ratio $[\mathrm{OR}]=3.4$ ) \\
\hline & \multirow{2}{*}{ Reoperation $<3$ months } & Ischemic tissue loss $(\mathrm{OR}=3.1)$ \\
\hline & & Minority status $(\mathrm{OR}=2.2)$ \\
\hline & \multirow[t]{2}{*}{ Readmission $<6$ months } & Ischemic tissue loss $(\mathrm{OR}=2.8)$ \\
\hline & & Renal failure $(\mathrm{OR}=2.3)$ \\
\hline \multirow[t]{6}{*}{ Taylor [3] } & \multirow{3}{*}{$\begin{array}{l}\text { Impaired ambulatory ability at the time of } \\
\text { presentation }\end{array}$} & 5-year mortality (hazard ratio $[\mathrm{HR}]=3.34$ ) \\
\hline & & Failure to eventually ambulate $(\mathrm{HR}=2.83)$ \\
\hline & & Loss of independent living status $(\mathrm{HR}=7.97)$ \\
\hline & \multirow[t]{3}{*}{ The presence of dementia } & Late mortality $(\mathrm{HR}=1.57)$ \\
\hline & & Failure to eventually ambulate $(\mathrm{HR}=2.20)$ \\
\hline & & Loss of independent living status $(\mathrm{HR}=5.44)$ \\
\hline \multirow[t]{5}{*}{ Taylor [4] } & \multirow[t]{5}{*}{ Surgical revascularization failure } & Impaired ambulatory status at presentation $(\mathrm{OR}=6.44)$ \\
\hline & & Presence of infrainguinal disease $(\mathrm{OR}=3.93)$ \\
\hline & & End-stage renal disease $(\mathrm{OR}=2.48)$ \\
\hline & & Presence of gangrene $(\mathrm{OR}=2.40)$ \\
\hline & & Hyperlipidemia $(\mathrm{OR}=0.56)$ \\
\hline
\end{tabular}

Table 3 Excluded studies $n=$ Number of Patients (Sample size)

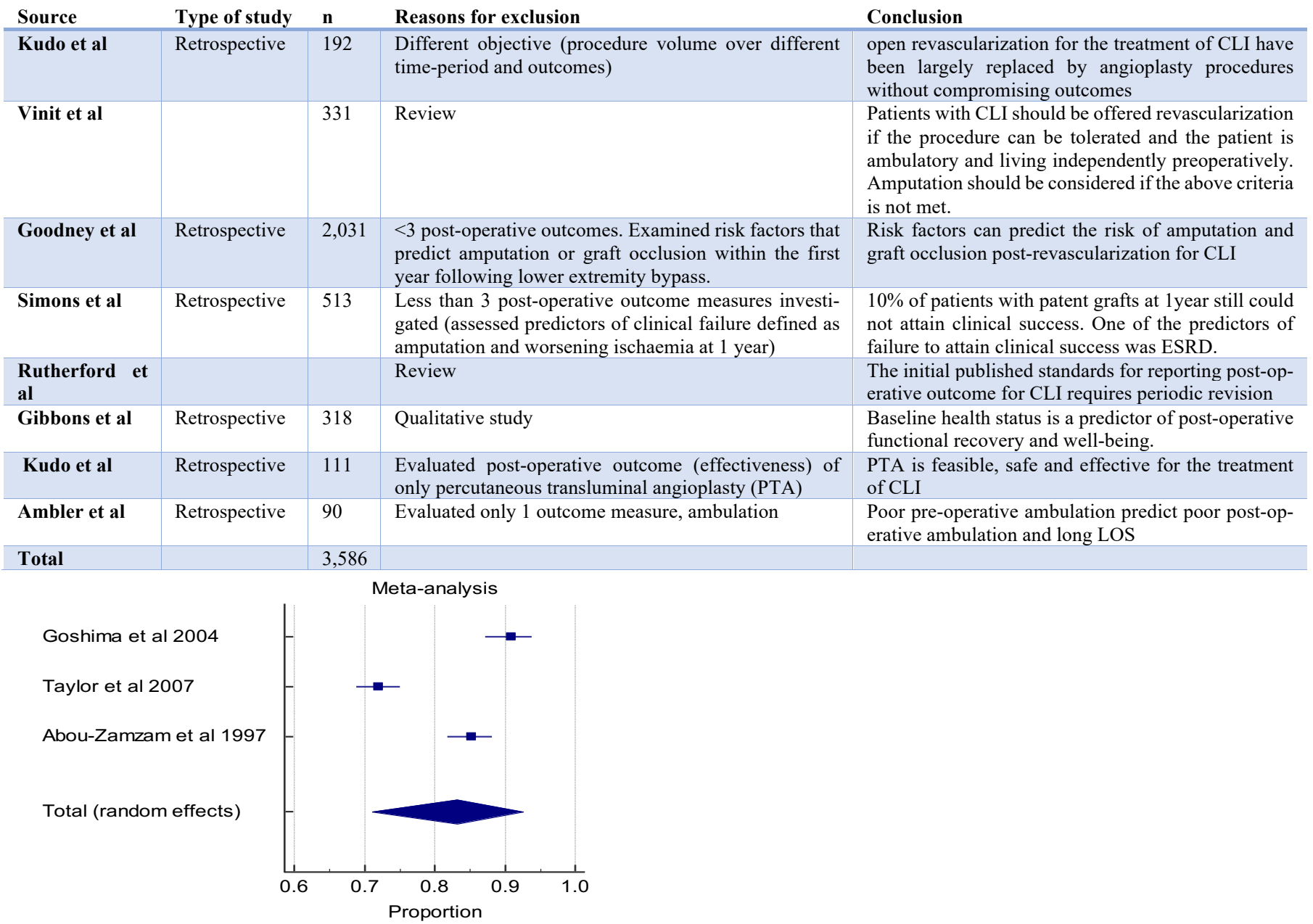

Figure 3a Forest plot of meta-analysis of the proportion estimates for post-operative outcome: limb salvage 
Special Article

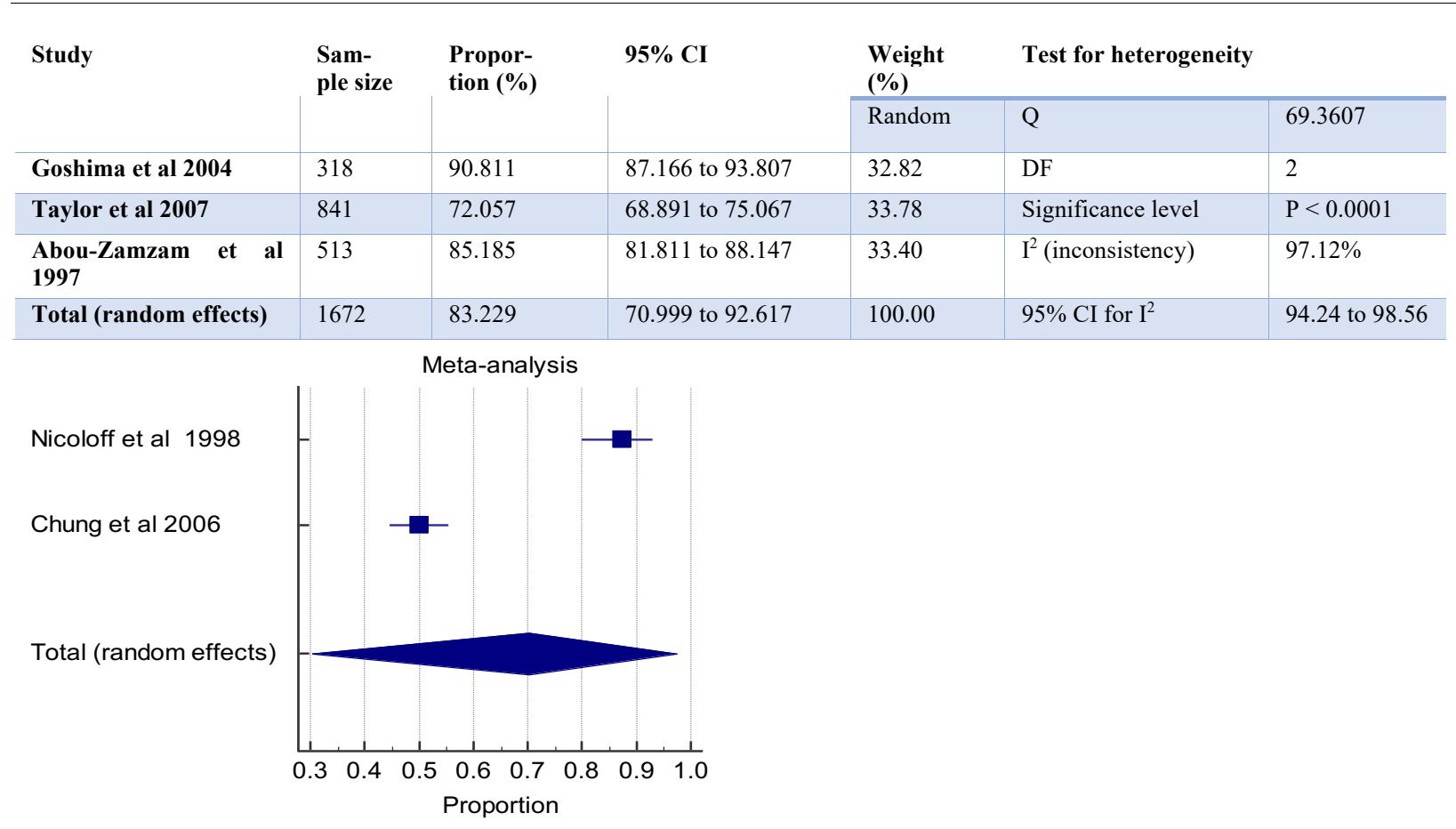

Figure 3b Forest plot of meta-analysis of the proportion estimates for post-operative outcome: primary graft patency

\begin{tabular}{|c|c|c|c|c|c|c|}
\hline \multirow[t]{2}{*}{ Study } & \multirow[t]{2}{*}{$\begin{array}{l}\text { Sam- } \\
\text { ple size }\end{array}$} & \multirow[t]{2}{*}{$\begin{array}{l}\text { Propor- } \\
\text { tion (\%) }\end{array}$} & \multirow[t]{2}{*}{$95 \%$ CI } & \multirow{2}{*}{$\begin{array}{l}\text { Weight } \\
\text { (\%) } \\
\text { Random }\end{array}$} & \multicolumn{2}{|c|}{ Test for heterogeneity } \\
\hline & & & & & Q & 59.3637 \\
\hline Nicoloff et al 1998 & 112 & 87.500 & 79.917 to 92.995 & 49.58 & DF & 1 \\
\hline Chung et al 2006 & 334 & 50.000 & 44.509 to 55.491 & 50.42 & Significance level & $\mathrm{P}<0.0001$ \\
\hline Total (fixed effects) & 446 & 60.492 & 55.797 to 65.048 & 100.00 & $\mathrm{I}^{2}$ (inconsistency) & $98.32 \%$ \\
\hline Total (random effects) & 446 & 70.187 & 30.262 to 97.240 & 100.00 & $95 \%$ CI for $\mathrm{I}^{2}$ & 96.22 to 99.25 \\
\hline
\end{tabular}

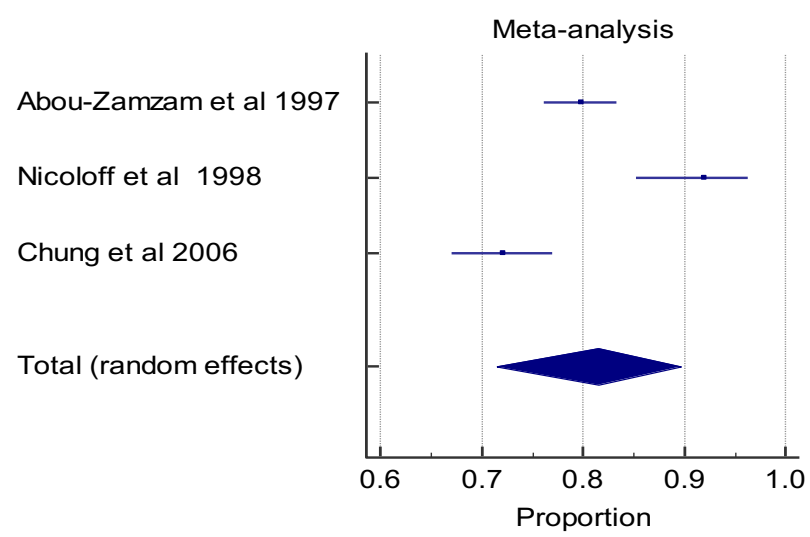

Figure 3c Forest plot of meta-analysis of the proportion estimates for post-operative outcome: ambulatory recovery

\begin{tabular}{|c|c|c|c|c|c|c|}
\hline \multirow[t]{2}{*}{ Study } & \multirow[t]{2}{*}{$\begin{array}{l}\text { Sam- } \\
\text { ple size }\end{array}$} & \multirow[t]{2}{*}{$\begin{array}{l}\text { Propor- } \\
\text { tion }(\%)\end{array}$} & \multirow[t]{2}{*}{$95 \%$ CI } & \multirow{2}{*}{$\begin{array}{l}\text { Weight (\% } \\
\text { ) } \\
\text { Random }\end{array}$} & \multicolumn{2}{|c|}{ Test for heterogeneity } \\
\hline & & & & & Q & 23.8936 \\
\hline Abou-Zamzam et al 1997 & 513 & 79.922 & 76.190 to 83.305 & 35.31 & $\mathrm{DF}$ & 2 \\
\hline Nicoloff et al 1998 & 112 & 91.964 & 85.293 to 96.260 & 30.25 & Significance level & $\mathrm{P}<0.0001$ \\
\hline Chung et al 2006 & 334 & 72.156 & 67.016 to 76.897 & 34.44 & $\mathrm{I}^{2}$ (inconsistency) & $91.63 \%$ \\
\hline Total (random effects) & 959 & 81.472 & 71.495 to 89.699 & 100.00 & $95 \%$ CI for I2 & 78.61 to 96.73 \\
\hline
\end{tabular}




\section{Special Article}

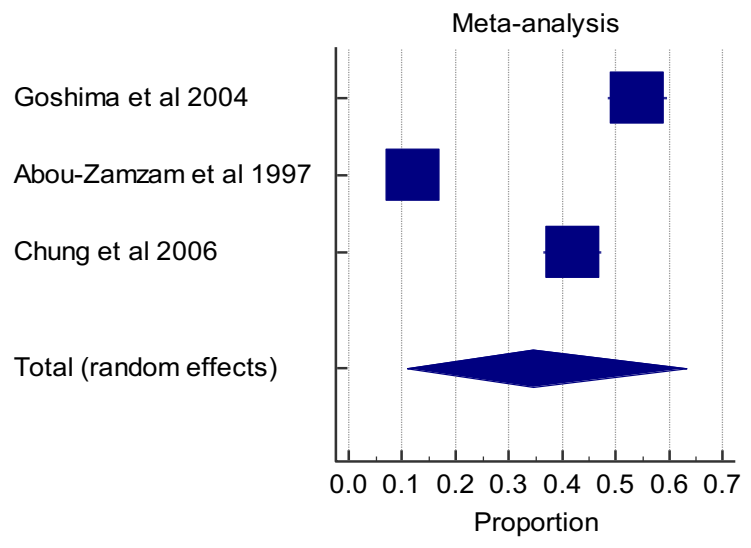

Figure 3d Forest plot of meta-analysis of the proportion estimates for post-operative outcome: wound healing

\begin{tabular}{|c|c|c|c|c|c|c|}
\hline \multirow[t]{2}{*}{ Study } & \multirow{2}{*}{$\begin{array}{r}\text { Sam- } \\
\text { ple size }\end{array}$} & \multirow{2}{*}{$\begin{array}{l}\text { Propor- } \\
\text { tion (\%) }\end{array}$} & \multirow[t]{2}{*}{$95 \% \mathrm{CI}$} & \multirow{2}{*}{$\begin{array}{c}\text { Weight (\% } \\
\text { ) } \\
\text { Random }\end{array}$} & \multicolumn{2}{|c|}{ Test of heterogeneity } \\
\hline & & & & & Q & 200.9922 \\
\hline Goshima et al 2004 & 318 & 54.088 & 48.437 to 59.662 & 33.28 & $\mathrm{DF}$ & 2 \\
\hline Abou-Zamzam et al 1997 & 513 & 12.086 & 9.393 to 15.224 & 33.43 & Significance level & $\mathrm{P}<0.0001$ \\
\hline Chung et al 2006 & 334 & 41.916 & 36.567 to 47.410 & 33.30 & $\mathrm{I}^{2}$ (inconsistency) & $99.00 \%$ \\
\hline Total (random effects) & 1165 & 34.571 & 10.951 to 63.280 & 100.00 & $95 \%$ CI for $\mathrm{I}^{2}$ & $\begin{array}{l}98.37 \\
99.39\end{array}$ \\
\hline
\end{tabular}

\section{DISCUSSION}

There is a high level of heterogeneity in the timelines for the various outcome measures in the papers evaluated. Multiple factors predict post-operative outcomes. Goshima et al studied the outcomes after infrainguinal bypass surgery to determine risk factors for adverse outcomes. Time to heal exceeded three months in $>50 \%$ of patients and diabetes mellitus among other factors was a major risk factor for prolong wound healing. ${ }^{2}$ In a study by Taylor et al, predictors of failure to achieve clinical success were the presence of gangrene, ESRD, hyperlipidaemia and impaired pre-operative ambulatory function. ${ }^{3}$ In that same study by Taylor et al, clinical success was defined as achieving all the following criteria: graft patency to the point of wound healing; limb salvage at one year; maintenance of ambulatory status for one year; and survival at six months. Despite $>70 \%$ limb salvage and graft patency at three years, only $44.4 \%$ of the patients achieved the composite endpoint of clinical success as stated above. ${ }^{3}$ Taylor et al again examined the determinants of functional outcome after revascularization for critical limb ischemia. Findings were that, at five years, graft patency and limb salvage were acceptable at $70 \%$. However, functional outcomes at five years were low, survival was only $41 \%$ with $70 \%$ ambulatory recovery. ${ }^{4}$ Sub-optimal post-operative ambulation was predicted by poor pre-operative ambulatory function. ${ }^{4}$
The large number of retrospective studies did not allow for standardization of timelines for outcome measurement. In terms of the type of revascularization procedure, many studies reported on only infra-inguinal bypass surgeries, but some studies reported also on supra-inguinal bypass as well as endovascular interventions. This makes it difficult to conduct comparative analysis. The small number of studies elligible for the meta-analysis resulted in restricted analysis and non-comprehensive results. There may be recall and selection bias due to the large number of retrospective studies.

\section{CONCLUSION}

There is wide variation in the parameters and timelines for reporting post-operative outcomes. This limits the effectiveness and quality of systematic review and accounts for the heterogeneity of the selected studies for the meta-analysis. Many more patients who were ambulant pre-operative continued to ambulate post-operative than those who were non-ambulant pre-operative. Diabetes mellitus was an important risk factor for prolonged wound healing, local wound complications and major amputation. Effective pre-operative glycemic control may improve post-operative outcome. 


\section{Special Article}

\section{ACKNOWLEDGEMENT}

The authors will like to thank all the staff of the Vascular and Endovascular Unit of Groote Schuur Hospital, University of Cape Town, South Africa for their support. We are also grateful to the Head of Department for his advice and support.

\section{REFERENCES}

1. Rutherford R, Flanigan D, Gupta S, Johnston K, Karmody A, Whittemore A. Suggested standards for reports dealing with lower extremity ischemia. $J$ Vasc Surg. 1986;4(1):80-94.

2. Goshima K, Mills J, Hughes J. A new look at outcomes after infrainguinal bypass surgery: traditional reporting standards systematically underestimate the expenditure of effort required to attain limb salvage. J Vasc Surg. 2004;39(2):330-335.

3. Taylor S, Cull D, Kalbaugh C, Cass A, Harmon S, Langan E. Critical analysis of clinical success after surgical bypass for lower-extremity ischemic tissue loss using a standardized definition combining multiple parameters: a new paradigm of outcomes assessment. J Am Coll Surg. 2007;204(5):831-838.

4. Taylor S, Kalbaugh C, Blackhurst D, Cass A, Trent E, EM L. Determinants of functional outcome after revascularization for critical limb ischemia: an analysis of 1000 consecutive vascular interventions. $J$ Vasc Surg. 2006;44(4):747-756.

5. Simons JP, Goodney PP, Nolan BW, et al. Failure to achieve clinical improvement despite graft patency in patients undergoing infrainguinal lower extremity bypass for critical limb ischemia Jessica. J Vasc Surg. 2010;51(6):1419-1424. doi:10.1016/j.jvs.2010.01.083.Failure
6. Nicoloff AD, Taylor LM, Mclafferty RB, Moneta GL, Porter JM. Patient recovery after infrainguinal bypass grafting for limb salvage. J Vasc Surg. 1997;27(2):256-266.

7. Rutherford R, Baker J, Ernst C, et al. Recommended standards for reports dealing with lower extremity ischemia: revised version. J Vasc Surg. 1997;26(3):517-538.

8. Slim K, Forestier D, Kwiatkowski F, Panis Y, Chipponi J. Methodological index for non-randomized studies (MINORS): development and validation of a new instrument. ANZ J Surg. 2003;73(9):712-716.

9. Abou-Zamzam A, Lee R, Moneta G, Taylor L, JM $P$. Functional outcome after infrainguinal bypass for limb salvage. J Vasc Surg. 1997;25(2):287-297.

10. Chung J, Bartelson B, Hiatt W, et al. Wound healing and functional outcomes after infrainguinal bypass with reversed saphenous vein for critical limb ischemia. J Vasc Surg. 2006;43(6):1183-1190.

11. Ambler G, Dapaah A, Al Zuhir N, et al. Independence and mobility after infrainguinal lower limb bypass surgery for critical limb ischemia. J Vasc Surg. 2014;59(4):983-987.

12. Goodney P, Nolan B, Schanzer A, et al. Factors associated with amputation or graft occlusion one year after lower extremity bypass in northern New England. Ann Vasc Surg. 2010;24(1):57-68.

13. Kudo T, Chandra F, Ahn S. The effectiveness of percutaneous transluminal angioplasty for the treatment of critical limb ischemia: a 10-year experience. $J$ Vasc Surg. 2005;41(3):423-435.

14. Gibbons G, Burgess A, Guadagnoli E, et al. Return to well-being and function after infrainguinal revascularization. J Vasc Surg. 1995;21(1):35-45. 